\title{
EFEITO DO ARMAZENAMENTO NA SUPERAÇÃO DA DORMÊNCIA DE SEMENTES DE FORRAGEIRAS
}

${ }^{1}$ Maycon Amim Vieira, ${ }^{2}$ Neimar Rotta Nagano, ${ }^{1}$ Fernando Donha Bianchi, ${ }^{1}$ Ronis Pereira da Silva

${ }^{1}$ Discente em Agronomia da Universidade do Oeste Paulista. ${ }^{2}$ Docente da Faculdade de Agronomia da Universidade do Oeste Paulista. E-mail: agrozoomav@gmail.com

\section{RESUMO}

O objetivo do estudo foi avaliar os efeitos do armazenamento na superação da dormência das cultivares de forrageiras mais comercializadas no Oeste Paulista através da avaliação da porcentagem de germinação, do IVG (Índice de Velocidade de Germinação) e do VC (Valor Cultural). O estudo foi realizado no laboratório de sementes da Universidade do Oeste Paulista (UNOESTE), em Presidente Prudente, SP. O mesmo compreende três tratamentos, o primeiro tratamento é avaliação aos 12 meses, o segundo aos 18 meses e o terceiro com 24 meses de armazenamento. As variedade de forrageiras utilizadas foram $B$. decumbens $\mathrm{cv}$. decumbens (Urochloa decumbens cv. Basilisk), B. brizantha cv. marandu (Urochloa brizantha cv. marandu), $B$. brizantha cv. xaraés (Urochloa brizantha cv. xaraés) e Panicum maximum cv. Mombaça. Em média geral a cultivar que apresentou melhores resultados nos três tratamentos foi a $B$. brizantha cv. marandu. Já o tratamento que apresentou melhor resultado, foi o 18 meses, sendo diferente significativamente dos demais, seguido do 12 meses que também teve diferença significativa do 24 meses.

Palavras-chave: Sementes, Germinação, Dormência, Armazenamento, Vigor.

\section{INTRODUÇÃO}

O Brasil apresenta condições edafoclimatica favoráveis ao desenvolvimento das pastagens, sendo esta a principal fonte de alimento tanto para bovinocultura de corte como de leite (SILVA et. al. 2013). Custódio et. al. (2012), afirma que o aumento da utilização de gramíneas forrageiras e a eficiência dos produtores de sementes resultaram no crescimento da indústria de sementes de forrageiras tropicais no Brasil, que se transformou em maior produtor, consumidor e exportador destas sementes, sendo que Urochloa (Brachiaria) e Panicum dominam o comércio nos mercados interno e externo.

Segundo Brites et. al. (2011), os gêneros Urochloa spp. (Brachiaria spp.) e Panicum spp. são de máximo interesse para a pecuária nacional, o que é bastante notável pela área cultivada, em que cerca de $70 \%$ a $80 \%$ da área com pastagens cultivadas no Brasil é formada com esses dois gêneros. Já Silva et. al.

Porém Lacerda et. al. (2010) afirma que cerca de $80 \%$ das áreas de pastagens brasileiras exibem um cenário de degradação, sendo uma das causas, a baixa taxa de germinação de 
sementes de espécies forrageiras. Já se sabe que muitas sementes não germinam mesmo quando submetidas a condições ambientais favoráveis, sendo chamado esse fenômeno de dormência.

Para Pereira et. al. (2013), esse fenômeno é uma das principais estratégias utilizadas por espécies vegetais para aumentar suas taxas de sobrevivência e o estabelecimento de plantas jovens, pois possibilita que a germinação ocorra apenas quando é mais provável que as condições para o estabelecimento das plântulas sejam mais adequadas.

Contudo, a maioria das gramíneas forrageiras tropicais é bastante afetada por essa dormência das sementes, a qual pode atrapalhar na determinação da sua qualidade fisiológica e a emergência das plântulas no campo e o estabelecimento de pastagens uniformes. Para Munhoz et. al. (2009), a expressão da dormência se associa a causas fisiológicas presentes em sementes recém-colhidas, progressivamente suprimidas durante o armazenamento. Costa et. al. (2011), afirma que no caso de sementes recém-colhidas, pede-se que permaneçam armazenadas por 6 a 9 meses, como forma de reduzir a intensidade da dormência.

Já Neto et. al. (2012), diz que a impermeabilidade do tegumento à água é um tipo de dormência muito comum e está relacionada a espécies de diversas famílias botânicas. É frequente a ocorrência de tegumentos duros, espessos e impermeáveis que limitam a penetração de água e oxigênio, oferecendo alta resistência física ao crescimento do embrião.

Portanto objetivo deste estudo foi avaliar os efeitos do armazenamento na superação da dormência das cultivares de forrageiras mais comercializadas no oeste paulista através da avaliação da porcentagem de germinação, do IVG (Índice de Velocidade de Germinação) e do VC (Valor Cultural).

\section{MATERIAL E MÉTODOS}

O presente trabalho foi conduzido no Laboratório de Análise de Sementes da Universidade do Oeste Paulista - UNOESTE em Presidente Prudente - SP. Foram utilizadas sementes altamente puras, doadas pela empresa SEMENTES FACHOLLI ${ }^{\circledR}$, localizada na cidade de Santo Anastácio - SP. Durante toda fase experimental os lotes foram armazenados em ambiente de laboratório (temperatura média de $25^{\circ} \mathrm{C}$ ). As espécies utilizadas foram: Urochloa decumbens (Brachiaria decumbens) cv. basilisk, Urochloa brizantha (Brachiaria brizantha) cv. xaraés, Panicum maximum cv. mombaça e Urochloa brizantha (Brachiaria brizantha) cv. marandu, produzidas na safra 2010/2011. Já os tratamentos foram compostos por três períodos de armazenamento, o primeiro 
tratamento foi avaliação aos 12 meses, o segundo tratamento com 18 meses e o terceiro com 24 meses de armazenamento.

Para o teste de germinação de cada período, foram coletado 400 sementes de cada cultivar dividas em quatro gerbox, sobre papel mata-borrão umedecido com água natural, gerando quatro repetições de cada cultivar. Sendo mantidas em germinador regulado para fornecer alternância de temperatura $(15 / 35$ ㄷ C) e fotoperíodo de 8 horas (BRASIL, 1992). Na qual foram consideradas germinadas as sementes através dos critérios de protrusão da raiz primária, e, plântulas normais, contagens aos 7, 14 e 21 dias (BRASIL, 1992) sendo os resultados expressos em porcentagem. Já para o IVG (Índice de Velocidade de Germinação), foram coletados os dados da germinação de cada contagem (7, 14 e 21 dias) e substituídos na formula:

$\operatorname{IVG}=\sum(\mathrm{n} / \mathrm{t})$

Onde:

$\mathrm{t}=$ número de dias da semeadura à primeira, a segunda e a terceira contagem.

$\mathrm{n}$ = número de plântulas normais computadas na primeira contagem, na segunda contagem e na terceira contagem.

Sendo que quanto maior o valor do IVG, maior a germinação média diária, melhor o tratamento. Para o teste de VC seguiu-se os parâmetros do BRASIL 2009.

Os dados obtidos foram submetidos à análise de variância pelo teste de $\mathrm{F}$, ao nível de $5 \%$ de probabilidade, e as medias comparadas pelo teste de Scott Knott utilizando ao programa estatístico sisvar (ANOVA, $p<0,05)$, segundo Gomes (1990).

\section{RESULTADOS}

A Tabela 1 expressa às porcentagens de germinação das cultivares $B$. decumbens cv. basilisk, $B$. brizantha cv. marandu, B. brizantha cv. xáraes e $P$. maximum cv. mombaça, submetidas a armazenamento em um período de 12 meses, de 18 meses e de 24 meses. 
Tabela 1. Porcentagem de germinação

\begin{tabular}{lcccc}
\multicolumn{1}{c}{ Cultivar } & $\mathbf{1 2}$ meses & $\mathbf{1 8}$ meses & $\mathbf{2 4}$ meses & Médias \\
\hline B. decumbens cv. basilisk & $63,50 \mathrm{Ba}$ & $67,00 \mathrm{Aa}$ & $30,00 \mathrm{Bb}$ & $53,50 \mathrm{~B}$ \\
B. brizantha cv. marandu & $87,50 \mathrm{Aa}$ & $84,75 \mathrm{Aa}$ & $71,50 \mathrm{Aa}$ & $81,25 \mathrm{~A}$ \\
B. brizantha cv. xaraés & $80,75 \mathrm{Aa}$ & $70,00 \mathrm{Aa}$ & $34,00 \mathrm{Bb}$ & $61,58 \mathrm{~B}$ \\
P. maximum cv. mombaça & $23,50 \mathrm{Cb}$ & $74,00 \mathrm{Aa}$ & $64,50 \mathrm{Aa}$ & $54,00 \mathrm{~B}$ \\
\hline Médias & $63,81 \mathrm{~b}$ & $73,93 \mathrm{a}$ & $50,00 \mathrm{C}$ & 62,58 \\
\hline CV (\%) 18,64 & & & \\
\hline Letras maiúsculas diferem na coluna e letras minúsculas na linha $(\mathrm{p}>0,05)$, para teste de contraste entre \\
médias Scott-Knott.
\end{tabular}

Podemos observar na tabela acima que, aos 12 meses de armazenamento as $B$. brizanthas foram as que apresentaram maior porcentagem de germinação com diferença significativa das demais. Aos 18 meses de armazenamento não houve diferença significativa entre as cultivares. Aos 24 meses, a que apresentou maior porcentagem de germinação foi a B. brizantha cv. marandu, seguida do P. maximum cv. mombaça, sendo ambas com diferença significativa das demais.

Em média geral a cultivar que apresentou melhor resultado de germinação nos três tratamentos foi a B. brizantha cv. marandu com $81,25 \%$ de germinação, com diferença significativa das demais. Já o tratamento que apresentou melhor resultado, foi o 18 meses com 73,93\% de germinação sendo diferente significativamente dos demais, seguido do 12 meses que também teve diferença significativa do 24 meses.

A Tabela 2 expressa os resultados do IVG (Índice de Velocidade de Germinação) das cultivares $B$. decumbens $\mathrm{cv}$. basilisk, $B$. brizantha $\mathrm{cv}$. marandu, $B$. brizantha $\mathrm{cv}$. xáraes e $P$. maximum cv. mombaça, submetidas a armazenamento em um período de 12 meses, de 18 meses e de 24 meses.

Tabela 2. IVG - Índice de Velocidade de Germinação

\begin{tabular}{lcccc}
\multicolumn{1}{c}{ Cultivar } & $\mathbf{1 2}$ meses & $\mathbf{1 8}$ meses & $\mathbf{2 4}$ meses & Média \\
\hline B. decumbens cv. basilisk & $7,11 \mathrm{Aa}$ & $9,34 \mathrm{Aa}$ & $3,92 \mathrm{Bb}$ & $6,79 \mathrm{~B}$ \\
B. brizantha cv. marandu & $9,50 \mathrm{Aa}$ & $11,88 \mathrm{Aa}$ & $8,93 \mathrm{Aa}$ & $10,10 \mathrm{~A}$ \\
B. brizantha cv. xaraés & $5,85 \mathrm{Ba}$ & $6,94 \mathrm{Ba}$ & $3,55 \mathrm{Ba}$ & $5,45 \mathrm{C}$ \\
P. maximum cv. mombaça & $3,24 \mathrm{Bb}$ & $10,52 \mathrm{Aa}$ & $8,72 \mathrm{Aa}$ & $7,49 \mathrm{~B}$ \\
\hline Média & $6,43 \mathrm{~b}$ & $9,67 \mathrm{a}$ & $6,28 \mathrm{~b}$ & 7,46 \\
\hline CV\% 26,64 & & \\
\hline Letras maiúsculas diferem na coluna e letras minúsculas na linha $(\mathrm{p}>0,05)$, para teste de contraste entre \\
médias Scott-Knott.
\end{tabular}


Observa-se na tabela acima que aos 12 meses, a que apresentou melhor IVG foi a $B$. brizantha cv. marandu, seguida da B. decumbens cv. basilisk, sendo ambas diferentes significativamente das demais. Aos 18 meses a que teve o pior IVG foi a B. brizantha cv. xaraés, sendo diferente significativamente. Já aos 24 meses, os cultivares que apresentaram melhores resultados foram a $B$. brizantha $\mathrm{cv}$. marandu e o $P$. maximum $\mathrm{cv}$. mombaça.

Nas médias, a que apresentou melhor IVG foi a cultivar B. brizantha cv. marandu, sendo o pior IVG da B. brizantha cv. xaraés. E o tratamento que melhor apresentou resultados foi o 18 meses.

Na Tabela 3 encontra-se os resultados de VC (Valor Cultural) das cultivares $B$. decumbens cv. basilisk, B. brizantha cv. marandu, B. brizantha cv. xáraes e P. maximum cv. mombaça, submetidas a armazenamento em um período de 12 meses, de 18 meses e de 24 meses.

Tabela 3. VC - Valor Cultural

\begin{tabular}{lcccc}
\multicolumn{1}{c}{ Cultivar } & $\mathbf{1 2}$ meses & $\mathbf{1 8}$ meses & $\mathbf{2 4}$ meses & Média \\
\hline B. decumbens cv. basilisk & $60,65 \mathrm{Ba}$ & $63,97 \mathrm{Aa}$ & $28,65 \mathrm{Bb}$ & $51,09 \mathrm{~B}$ \\
B. brizantha cv. marandu & $84,30 \mathrm{Aa}$ & $81,70 \mathrm{Aa}$ & $68,90 \mathrm{Aa}$ & $78,30 \mathrm{~A}$ \\
B. brizantha cv. xaraés & $78,57 \mathrm{Aa}$ & $68,10 \mathrm{Aa}$ & $33,10 \mathrm{Bb}$ & $59,92 \mathrm{~B}$ \\
P. maximum cv. mombaça & $22,20 \mathrm{Cb}$ & $70,00 \mathrm{Aa}$ & $61,02 \mathrm{Aa}$ & $51,07 \mathrm{~B}$ \\
\hline Média & $61,43 \mathrm{~b}$ & $70,94 \mathrm{a}$ & $47,92 \mathrm{a}$ & 60,09 \\
\hline CV\% 18,55 & & & &
\end{tabular}

Letras maiúsculas diferem na coluna e letras minúsculas na linha $(p>0,05)$, para teste de contraste entre médias Scott-Knott.

Aos 12 meses, os que apresentaram melhores resultados de VC foram B. brizantha. Aos 18 meses não teve diferença significativa. Aos 24 meses os que apresentaram melhores VC foram os cultivares $B$. brizantha cv. marandu e o P. maximum cv. mombaça, sendo diferentes significativamente das demais.

No geral, a B. brizantha cv. marandu é a que melhor apresentou VC em todos os períodos, e o tratamento que apresentou melhor VC foi o 18 meses.

\section{DISCUSSÃO}

Observa-se que as sementes, aos 12 meses apresentaram maior dormência que aos 18 meses, ou seja, as sementes tiveram uma menor germinação e com menor velocidade que aos 18 meses. Estes resultados são semelhantes a Rivero \& Espinosa (1988), na qual descobriram, em seus estudos, que as sementes tinham dormência profunda logo após serem colhidas e que a 
mesma foi decrescendo com o armazenamento. Gonzáles et. al. (1994) observaram em suas pesquisas que as sementes apresentavam baixa porcentagem de germinação no início do armazenamento, atingindo o valor máximo de germinação depois de um determinado tempo de armazenamento. Também Renard \& Capelle (1976), notaram que a germinação aumentava com o armazenamento por até 18 meses.

Pode-se notar também que do 18 o mês para o 24 o mês, houve uma queda em todos os índices. Isto pode ser explicado por Garcia \& Cícero (1992), na qual também observou que, nas gramíneas forrageiras tropicais, a dormência esta associada às causas fisiológicas presentes em sementes recém colhidas, sendo progressivamente superadas durante o armazenamento, porém deve-se levar em conta que longos períodos de armazenamento podem levar a sementes a perderem o seu vigor.

Segundo Carvalho \& Nakagawa (2000), em alguns de seus trabalhos, diz que as sementes apresentam maior viabilidade e vigor por ocasião da maturidade fisiológica. A partir deste instante vão ocorrer evidentemente mudanças fisiológicas e bioquímicas graduais que ocasionam a deterioração e a perda de vigor. Eles relatam também que o genótipo das plantas determinam parcialmente o vigor apresentado pelas sementes em cada cultivar. Isso explica o porquê da cultivar B. brizantha cv. marandu, ter se destacado em todos os tratamentos.

\section{CONCLUSÃO}

Pelo presente trabalho, pode-se concluir que, a Brachiaria brizantha cv. marandu foi a que melhor respondeu ao armazenamento. E até ao 18으 mês todas as cultivares passam por uma superação de dormência natural provocada pelo armazenamento, porém a partir do 18o mês, a porcentagem de germinação, a velocidade de germinação e o valor cultural foram reduzidos.

\section{REFERÊNCIAS}

BRASIL, Ministério da Agricultura e Reforma Agrária. Regras para análise de sementes. Brasília: SNDA/DNDV/CLAV, 2009. 395p.

BRASIL, Ministério da Agricultura e Reforma Agrária. Regras para análise de sementes. Brasília: SNDA/DNDV/CLAV, 1992. 165p.

BRITES, F. H. R.; SILVA JÚNIOR, C. A. \& TORRES, F. E. Germinação de sementes comum, escarificada e revestida de diferentes espécies forrageiras tropicais. Biosci. J. Uberlândia, v. 27, n. 4, p. 629-634, July/Aug. 2011. 
COSTA, C. J.; ARAÚJO, R. B. \& BÔAS, H. D. C. V. Tratamentos para a superação de dormência em sementes de Brachiaria humidicola (Rendle) Schweick Pesq. Agropec. Trop., Goiânia, v. 41, n. 4, p. 519-524, out./dez. 2011.

CUSTÓDIO, C. C.; DAMASCENO, R. L. \& NETO, M. B. N. Imagem digitalizada do teste de tetrazólio em Brachiaria. Revista Brasileira de Sementes, vol. 34, no 2 p. 334 - 341, 2012.

http://dx.doi.org/10.1590/S0101-31222012000200020

FREITAS, A. R., LOPES, J. C., MATHEUS, M. T., MENGARDA, L. H. G., VENANCIO, L. P. \& CALDEIRA, M. V. W. Superação da dormência de sementes de jatobá. Pesq. flor. bras., Colombo, v. 33, n. 73, p. 85-90, jan./mar. 2013.

GARCIA, J. \& CÍCERO, S. M. Superação de dormência em sementes de Brachiaria brizantha cv. Marandu. Scientia Agrícola, Piracicaba, v. 49, n. I, p. 9-13, 1992.

GONZÁLEZ, E.; MENDOZA, F. \& TORRES, R. Efeito do armazenamento e escarificação química e mecânica em sementes de Brachiaria decumbens cv. Basilisk. Pastagens e Forragens. p. 35-43, 1994.

LACERDA, M. J. R., CABRAL, J. S. R.; SALES, J. F.; FREITAS, K. R. \& FONTES, A. J. Superação da dormência de sementes de Brachiaria brizantha cv. "Marandu". Semina: Ciências Agrárias, Londrina, v. 31, n. 4, p. 823-828, out./dez. 2010.

LIMA, J. S.; CHAVES, A. P.; MEDEIROS, M. A.; RODRIGUES, G. S. O. \& BENEDITO, C. P. B. Métodos de superação de dormência em sementes de flamboyant (Delonix regia). Revista Verde (Mossoró - RN - Brasil), v. 8, n. 1, p. 104 - 109, jan/mar de 2013.

MOREIRA, N. C. \& NAKAGAWA, J. Sementes: Ciência, tecnologia e produção. Jaboticabal. ed. 4. 588p. 200.

MUNHOZ, R. E. F., ZONETTI, P. C. \& ROMAN, S. Superação da dormência em sementes e desenvolvimento inicial em Brachiaria brizantha cv. MG5 através da escarificação com ácido sulfúrico. Revista em Agronegócios e Meio Ambiente, v.2, n.1, p. 55-67, jan./abr. 2009.

PEREIRA, S. R.; LAURA, V. A. \& SOUZA, A. L. T. Superação de dormência de sementes para restauração florestal. Pesq. agropec. bras., Brasília, v.48, n.2, p.148-156, fev. 2013.

RENARD, C. \& CAPELLE, P. A germinação das sementes de Brachiaria ruziziensis. Jornal botânico. Austrália. p. 437-446, 1976.

RIVERO, L. M. \& ESPINOSA, J. Duração da dormência de Brachiaria decumbens. Pastagens tropicais, p. 20-23, 1988.

SILVA, A. B.; LANDGRAFI, P. R. C. \& MACHADO, G. W. O. Germinação de sementes de brachiária sob diferentes concentrações de giberelina. Semina: Ciências Agrárias, Londrina, v. 34, n. 2, p. 657-662, mar./abr. 2013. 